\title{
Self-sustained vibrations in volcanic areas extracted by Independent Component Analysis: a review and new results
}

\author{
E. De Lauro, S. De Martino, M. Falanga, and M. Palo \\ Dipartimento di Ingegneria Industriale, Salerno University, Ponte Don Melillo street, 84084, Fisciano (SA), Italy \\ Received: 31 May 2011 - Revised: 27 October 2011 - Accepted: 14 November 2011 - Published: 8 December 2011
}

\begin{abstract}
We investigate the physical processes associated with volcanic tremor and explosions. A volcano is a complex system where a fluid source interacts with the solid edifice so generating seismic waves in a regime of low turbulence. Although the complex behavior escapes a simple universal description, the phases of activity generate stable (self-sustained) oscillations that can be described as a nonlinear dynamical system of low dimensionality. So, the system requires to be investigated with non-linear methods able to individuate, decompose, and extract the main characteristics of the phenomenon. Independent Component Analysis (ICA), an entropy-based technique is a good candidate for this purpose. Here, we review the results of ICA applied to seismic signals acquired in some volcanic areas. We emphasize analogies and differences among the self-oscillations individuated in three cases: Stromboli (Italy), Erebus (Antarctica) and Volcán de Colima (Mexico). The waveforms of the extracted independent components are specific for each volcano, whereas the similarity can be ascribed to a very general common source mechanism involving the interaction between gas/magma flow and solid structures (the volcanic edifice). Indeed, chocking phenomena or inhomogeneities in the volcanic cavity can play the same role in generating selfoscillations as the languid and the reed do in musical instruments. The understanding of these background oscillations is relevant not only for explaining the volcanic source process and to make a forecast into the future, but sheds light on the physics of complex systems developing low turbulence.
\end{abstract}

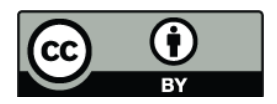

Correspondence to: M. Falanga (rosfal@sa.infn.it)

\section{Introduction}

The ultimate goal in Volcanology is to forecast eruptions. Since at least three decades, the rising number of observed phenomena associated with eruptions led many scientists to believe that it could be possible to obtain a simple set of empirical relationships suitable for this purpose. This optimistic goal vanished because of the complexity of the physical framework that has not a well defined theoretical description yet. Indeed, volcanoes can be schematized as fluiddynamical systems developing turbulence, characterized by a complex thermodynamic behavior, whose activity is, from a seismological point of view, readable in the interaction of flow (sources) with the solid edifice. This is surely true for both basaltic and andesitic volcanoes in the stationary regime and in the paroxysmal phase. Moreover, even simple phenomenological aspects cannot be reproduced in laboratory experiments because of the complexity which involves many time and spatial length scales.

Despite this, "collective" phenomena occur, such as volcanic tremor, long period (LP) seismicity, and explosionquakes which often precede, accompany and follow the eruptive process. The fluid-dynamical system that operates within the magmatic plumbing system has in general infinitely many degrees of freedom. Nevertheless, the phases of volcanic activity (tremor and explosion) we analyze generate globally organized stable oscillations that can be described by representative degrees of freedom at a coarsegrained level. In other words, the physical processes causing the seismic waves in an active volcano are related to the fluid flows which induce self-sustained oscillations (i.e., seismicity) in the conduit's wall if there is a suitable impingement geometry and, at low Reynolds numbers, the convective scales match the viscous ones (Villermaux and Hopfinger, 1994; Maurel et al., 1996; De Lauro et al., 2008). Several mechanisms for tremor generation have been proposed

Published by Copernicus Publications on behalf of the European Geosciences Union and the American Geophysical Union. 
including bubble growth or collapse, jerky crack propagation, oscillations of magma chambers, resonance of fluidfilled cracks and flow-induced oscillations of conduits (McNutt, 2005). The explosions are due to the formation and ascent of slugs within the shallow plumbing system by means of the coalescence of diffusing bubbles (Chouet et al., 2003; Bottiglieri et al., 2005).

Due to the complexity of the phenomena governing volcanic activity, non-linear models seem to be more adequate to describe the volcano's dynamics. Specifically, nonlinear processes similar to those producing self-oscillations in string and wind instruments such as violins and organ pipes have been invoked (Woodhouse, 1996; De Lauro et al., 2007) to explain the generation of volcanic signals. Julian (1994) proposed flow-induced non-linear oscillations in channels transporting volcanic fluids as a possible generating mechanism for sustained tremor as well as transient signals. According to that model, the oscillations are sustained by a cyclic feedback, which is caused by variations in the flow speed and pressure. Balmforth et al. (2005) extended the flow-induced non-linear oscillations model of Julian by including the dynamical behaviour of the fluid and the elasticity of the conduit's walls. Similar non-linear models were also developed for more complex fluids such as liquid/gas two-phase flows (Fujita et al., 2004; Iwamura and Kaneshima, 2005). Recently, De Lauro et al. (2009c) introduced a non-linear model based on the Andronov's oscillator (Andronov et al., 1966), suitable to describe the selfsustained vibrations of resonant structures, in terms of clusters of non-linearly excited classical oscillators.

However, the understanding of the source mechanisms causing the ground oscillations and the characteristics of the resulting signals has to be recovered from the experimental data, facing a typical inverse problem. The complexity of the topographic volcanic structure generally reflects into the high-frequency seismic wavefield $(>0.5 \mathrm{~Hz})$, making the investigation of its properties very hard. Indeed, the presence of heterogeneities can affect the recorded signals, which might display low spatial coherence and site dependence. Methods based on the concepts of complexity, statistics, and ergodicity are exploited to extract the relevant properties of the source mechanism re-conducting the complexity of the waveforms to simpler and smooth signals, whose suitable combinations rebuild the original recordings. A non-linear approach is required because linear analysis is not a good indicator of the behavior of non-linear systems. There are many methods used for this aim, and Independent Component Analysis (ICA) represents a particularly powerful one. ICA performs a blind separation of statistically independent signals adopting the intuitive notion of maximum nonGaussianity. This is achieved involving fourth-order statistics techniques prone to detect nonlinearity.

We review the results achieved by applying ICA to seismic signals recorded at different volcanoes (basaltic and andesitic), critically individuating in their complex behaviour the basic elements that can lead to a simple universal description of the volcano activity. We organize the paper first illustrating the ICA method, then showing its application to observed seismic signals recorded at three different volcanoes: Stromboli (Italy), Erebus (Antarctica) and Volcán de Colima (Mexico). Finally, the main conclusions are summarized.

\section{Independent component analysis}

The complexity of the seismic signals recorded in volcanic areas requires to be investigated in a time-domain approach, which is appropriate for retrieving non-linearity. Indeed, there are physical systems with very similar Fourier transform but which have completely different in waveforms (see, e.g. De Lauro et al., 2005b). There exist many techniques developed for quantitatively characterizing the complexity of a dynamical system from a given finite set of (noisy) measurements. Certain methods are computationally less demanding but statistically suboptimal in many situations, while statistically optimal methods can have a very high computational demand or cannot be realized in many practical situations. Then, the choice of a suitable estimation method mainly depends on the assumed data model, which may be either linear or non-linear, dynamic or static, random or deterministic. Corresponding methods include Principal Component Analysis (PCA), Singular Value Decomposition (SVD) (see, e.g. Hyväinen et al., 2001; Wall et al., 2003) and methods derived from previous ones such as Singular Spectrum Analysis (SSA) for univariate data and its multivariate extension Multi-channel SSA (MSSA) (see, e.g. Elsner and Tsonis, 1996). We remind that PCA transforms a number of (possibly) correlated variables into a (smaller) set of uncorrelated variables called principal components. Indeed, it projects the high-dimensional data onto a new coordinate system with fewer dimensions. The largest fraction of variance of the original data is taken care of by the first coordinate or principal component and each succeeding component accounts for as much of the remaining variability as possible (Hyvärinen et al., 2001). The idea of SSA relies on elementary linear algebra: a basic understanding of concepts such as matrixvector products, eigenvalues and eigenvectors is hence necessary. In other words, it takes into account the information contained in the covariance matrix. MSSA, a combination of SSA and PCA also takes cross-correlations into account.

While the previously described methods are based on second-order statistics (covariances), the intuitive notion of maximum non-Gaussianity is used in ICA involving higher-order statistics. Specifically, ICA is an entropybased technique, introduced in the early 1980s in a neurophysiological setting (Hérault and Ans, 1984), to separate mixtures of signals (for more details, see Hyväinen et al. (2001) and many papers cited therein). The central idea is to the find underlying components from multivariate 
(multidimensional) statistical data on the basis of their statistical independence evaluated by using 4th-order statistical properties.

Let us explain in brief the mathematical setting on which ICA is based. We suppose to have $m$ different time series $\mathbf{x}$ that we hypothesize to be the linear superposition of $n \mathrm{mu}-$ tually independent unknown signals s. The mixing is represented by a constant unknown matrix A. This mixing is essentially due to path, noise, instrumental transfer functions, etc. The hypothesis is to have linear mixtures of some independent dynamical systems. If the mixing has to be linear, nothing is assumed with respect to the component signals, which can be generated by linear or non-linear dynamical systems (such as a harmonic oscillator or Van der Pol oscillator). We assume an instantaneous mixing model, thus we neglect any time delay that may occur in the mixing. Formally, the mixing model is written as

$\mathbf{x}=\sum_{j=1}^{n} a_{i j} s_{j}+v$,

where $\mathbf{x}$ is an observed $m$-dimensional vector, and $\mathbf{s}$ is an $n$-dimensional random vector to be estimated whose components are assumed to be mutually independent. $\mathbf{A}$ is a constant $m \times n$ matrix to be estimated. The additive noise term $v$ is, generally, incorporated in the sum as one of the source signals. Supposing that the number of sources is equal to the number of mixtures, the aim of ICA is to obtain a separating matrix $\mathbf{W}=\mathbf{A}^{-1}$ in such a way that the vector $\mathbf{y}=\mathbf{W} \mathbf{x}$ is an estimate $\mathbf{y} \sim \mathbf{s}$ of the original independent signals.

The basic ICA model requires the following assumptions: all the independent components (ICs), with the possible exception of one of them, must be non-Gaussian; the number of the observed linear mixtures must be at least as large as the number of independent components; the matrix A must be of full column rank.

ICA is a statistical model based on the central limit theorem, which establishes that the distribution of a sum of independent random variables tends under certain conditions towards a Gaussian distribution. Hence, the main idea of the ICA model is to maximize the non-Gaussianity (superGaussianity or sub-Gaussianity) to extract the independent components.

Some heuristic approaches have been proposed in the literature to achieve the separation. Among them, a good measure of independence is given by the negentropy $J(z)$. It relays upon the information-theoretic quantity of differential entropy $H$ of a random vector and is defined as follows:

$J(z)=H\left(z_{\text {gauss }}\right)-H(z)$,

where $z$ is a random variable and $z_{\text {gauss }}$ is a Gaussian random variable with the same covariance matrix as $z$. The estimation of the negentropy is difficult and, in practice, some approximations must be introduced (Hyvärinen et al., 2001). These approximations involve the estimate of 4th-order statistical moments.
In our case, the implementation of ICA is achieved by means of the fixed-point algorithm, referred to as FastICA. This algorithm contributed to the application of ICA to a variety of phenomena due to its computational efficiency.

Rigorously, this algorithm is based on an approximating Newton iteration scheme. The FastICA learning rule finds a direction, i.e. a unit vector $\mathbf{w}$ such that the projection $\mathbf{w}^{T} \mathbf{x}$ maximizes the non-Gaussianity of the single estimated source $y$. The non-Gaussianity is here measured by the approximation of the negentropy given by

$J_{G}(\mathbf{w})=\left[E\left\{G\left(\mathbf{w}^{T} \mathbf{x}\right)\right\}-E\{G(v)\}\right]^{2}$,

where $G$ is a suitable non-quadratic function, $\mathbf{w}$ is an $m$ dimensional (weight) vector, $\mathbf{x}$ represents our mixture of signals, and $E\left\{\left(\mathbf{w}^{T} \mathbf{x}\right)^{2}\right\}=1, v$ is a standardized Gaussian random variable. Maximizing $J_{G}$ allows to find one independent component. This algorithm requires a preliminary whitening of the data, which consists of obtaining new mixtures (v), which are uncorrelated and have unit variance. Whitening is accomplished by PCA.

The one-unit fixed-point algorithm for finding the weight $\mathbf{w}$ is (Hyvärinen et al., 2001):

$\mathbf{w}^{*}=E\left[\mathbf{v} g\left(\mathbf{w}_{i}^{T} \mathbf{v}\right)\right]-E\left[g^{\prime}\left(\mathbf{w}_{i}^{T} \mathbf{v}\right)\right] \mathbf{w}_{i}$

$\mathbf{w}_{i}=\mathbf{w}_{i}^{*} /\left\|\mathbf{w}_{i}^{*}\right\|$,

where $g(\cdot)$ is a suitable non-linearity, in our case $g(y)=$ $\tanh (y)$, and $g^{\prime}(y)$ is its derivative with respect to $y$. The algorithm of the previous equations estimates just one of the ICs. To estimate several independent components, we need to run the one-unit FastICA algorithm using several units (e.g. neurons) with weight vectors $\mathbf{w}_{1}, \ldots, \mathbf{w}_{n}$. To prevent different vectors from converging to the same maximum we must decorrelate the outputs $\mathbf{w}_{1}^{T} \mathbf{x}, \ldots, \mathbf{w}_{n}^{T} \mathbf{x}$ after each iteration. In specific applications it may be desired to use a symmetric decorrelation, in which vectors are not privileged over the others. This can be accomplished by the classical method involving matrix square roots. The main advantages of the FastICA algorithm is that its convergence is very fast (cubic or at least quadratic) and that the adopted contrast function has good statistical properties, such as robustness. FastICA being a heuristically-based implementation of ICA does not require "a priori" additional assumptions (such as, e.g. sparseness of spectral signals, assumptions of nonnegativity of the source signals) about the pure components.

There are other approaches based on similar ideas as ICA, such as least-dependent component analysis (MILCA algorithm, Stögbauer et al., 2004) or non-Gaussian component analysis (SNICA algorithm, Kawanabe et al., 2007). They use a Mutual Information (MI) estimator instead of nonGaussianity to find the least dependent components under a linear transformation.

It is important to underline that ICA with the FastICA algorithm is very efficient to extract self-oscillations and periodic signals from noise or non-linear mixtures up to an amplitude ratio smaller than three order of magnitude, making 
it a powerful tool in the case of volcanic signals (De Lauro et al., 2005b). We remark that ICA has already been successfully applied to a variety of experimental signals from biology to geophysics (see e.g. Fiori, 2003). For example, ICA has been recently applied by Orihara et al. (2009) to distinguish seismic electric signals (SES) - which are lowfrequency electric signals preceding earthquakes originally found in Greece (see Varotsos and Alexopoulos, 1984a, b) from artificial noise. For the volcanic-seismic swarm activity in 2000 in the Izu Island region in Japan (Uyeda et al., 2009) analyzed in natural time (which is a new time domain introduced in Varotsos et al., 2002), the seismicity subsequent to the SES recorded and identified the occurrence time of the first major earthquake (magnitude class 6 on 1 July 2000) with an accuracy of a few days, in agreement with the procedure suggested by Varotsos et al. (2006). More recently, a convolutive extension of ICA has been applied to the detection of long-period events at the Campi Flegrei volcano (Italy) (see, Ciaramella et al., 2011). Very interesting results of ICA applications were also obtained for the acoustical and mechanical vibrational fields in an organ pipe (De Lauro et al., 2007) or the optical depth and aerosol index in atmosphere (De Martino et al., 2002a; Cuomo et al., 2009). Major details of the application of this technique to dynamical systems and interesting extensions of it to a non-linear model can be found in De Lauro et al. (2005b), Lin et al. (2005), Ciaramella et al. (2006) and Lin and Tung (2007).

Here, we critically review the results relative to three selected volcanic areas deriving some constraints on the source model. Similar studies were performed at Merapi (Cabras et al., 2008) and Etna (Cabras et al., 2010).

The independent oscillations in seismology are often characterized in terms of polarization properties. Briefly, the numerical estimate of the polarization vector is based on the diagonalization of the covariance matrix of the three components of motion. The eigenvector corresponding to the maximum eigenvalue defines the polarization vector described by azimuth, dip and rectilinearity (RL) in a reference frame defined by the East-West/North-South plane and its normal (vertical direction). This method provides in case of longitudinal waves an estimate of the source localization.

\section{Stromboli}

Stromboli is a volcanic island of the Aeolian arc in the Tyrrhenian Sea (Italy). This volcano rises about $924 \mathrm{~m}$ a.s.l., most of the products are ejected from the craters placed on a terrace at $700 \mathrm{~m}$ a.s.l. It is characterized by persistent explosive activity superimposed to a background volcanic tremor. This activity is so characteristic to be named "Strombolian" also when appearing at other volcanoes (Aster et al., 2003; De Lauro et al., 2009a, b; Patanè et al., 2008). Sometimes, it is interrupted by effusive phases and/or by big explosive

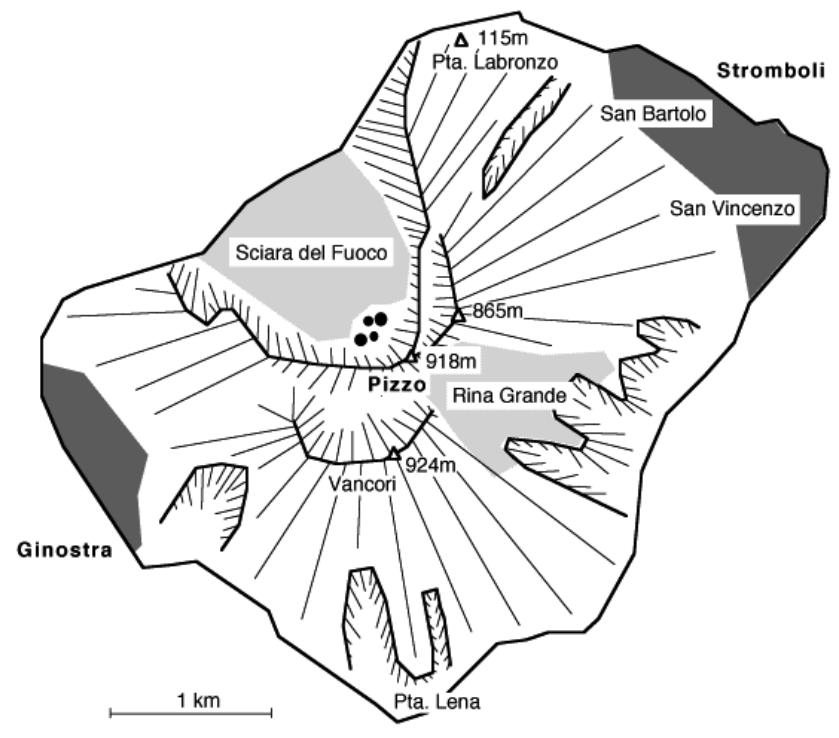

Fig. 1. Map of Stromboli volcano (Italy), where the vents are indicated by black dots (from http://www.swisseduc.ch/stromboli/ volcano/geogr/maps-en.html).

events; the last two occurred on December 2002 and February 2007.

The seismic wavefield at Stromboli has been extensively studied by using advanced signal processing techniques. In particular, Del Pezzo et al. (1992), Chouet et al. (1997), and Acernese et al. $(2003,2004)$ studied the composition of the high-frequency wavefield $(>0.5 \mathrm{~Hz})$ associated with the explosion quakes. Chouet et al. (2003) investigated the seismic wavefield associated with very long period events (VLP), and retrieved the equivalent elastic source mechanism which includes both moment tensor and single force components. These authors estimated for a typical VLP event a volume change on the order of $200 \mathrm{~m}^{3}$ and a single vertical force with a magnitude on the order of $10^{8} \mathrm{~N}$. This model is compatible with a magma movement perched above the source centroid position, in response to the rise of a gas slug into the conduit. More recently, De Martino et al. (2011b), studying the eruptive process of both the crises of 2002 and 2007, have also found a precursor of the effusion in the tidal frequency regime, indicating that a modification of the local rheology represents the first response of the system to the departure from a stationary regime.

Although it now appears clear that the magmatic processes are associated with the low-frequency band $(<0.4 \mathrm{~Hz})$, thehigh frequency band, generally associated with the vibrations of the conduit, is a direct consequence of a turbulent degassing, that can be considered as an epiphenomenon of the magma dynamics. Therefore, the application of ICA intends to recover the simplest oscillations related to the vibrations of the volcanic edifice strictly connected to the source process. 

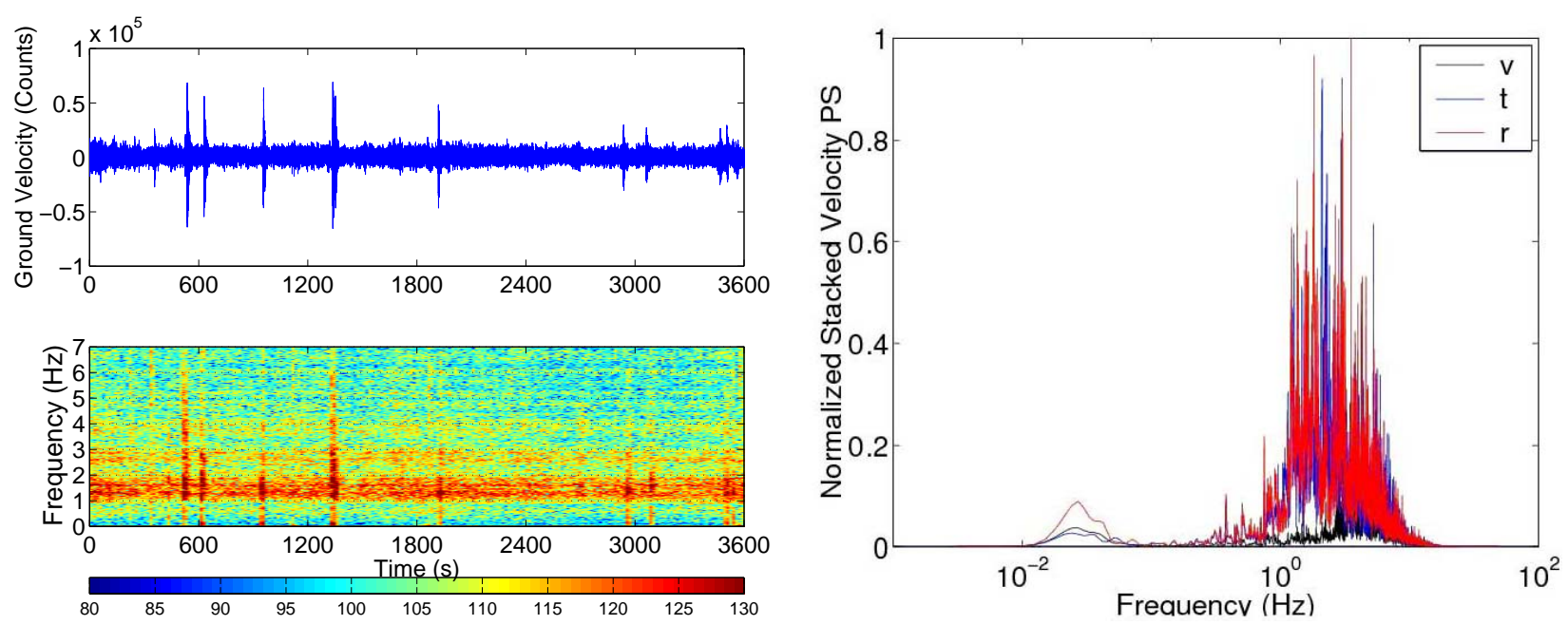

Fig. 2. Left panel: an example of seismic recordings acquired at Stromboli in 1997. Explosion-quakes are visible superposed to the background volcanic tremor (upper panel) and in the related spectrogram (lower panel). The spectrogram was calculated using a Fast Fourier Transform (FFT) with a sliding Hanning windowing (from De Lauro et al., 2008). Right panel: the normalized stacked power spectrum of the seismic series shows that the energy is mainly concentrated into three distinct frequency bands (different colors regard the radial $(r$ ), transverse $(t)$ and vertical $(v)$ directions of motion).
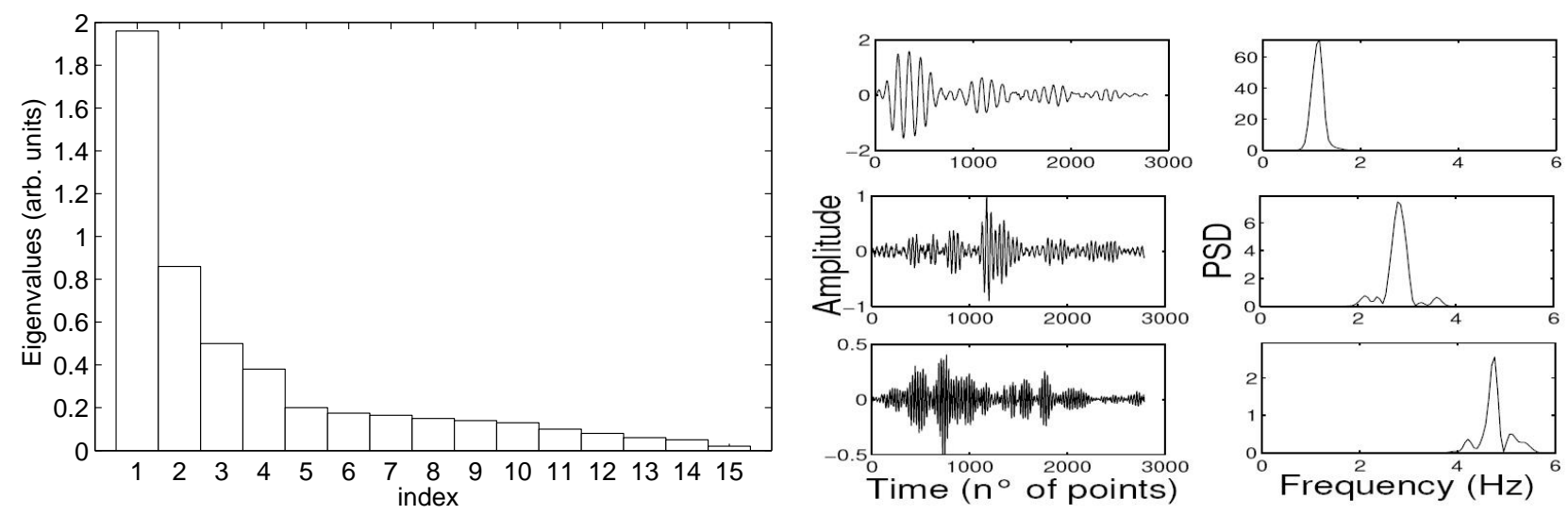

Fig. 3. Strombolian explosion-quakes in the higher frequency band $(f>0.5 \mathrm{~Hz})$. Left panel: PCA results. A few principal components contain essentially all the dynamically relevant information. Right panels: ICA results. Only three components are independent with a specific and well-defined spectral content (from Acernese et al., 2004).

\subsection{Spectral analysis}

A map of Stromboli volcano is displayed in Fig. 1, whereas Fig. 2 contains an example of seismogram and frequencies involved in the seismicity recorded during a stationary phase of the activity at Stromboli.

It can be deduced that volcanic tremor and explosionquakes share the same spectral content, which is mainly concentrated in distinct frequency bands (see Fig. 2-right panel): the high frequency region $f>0.5 \mathrm{~Hz}$ that is the most energetic band (as already described in several previous paperssee Ciaramella et al. (2004) and references therein); the intermediate band $0.1<f<0.5 \mathrm{~Hz}$ (discussed by De Lauro et al., 2005a) and the very low frequency band $<0.1 \mathrm{~Hz}$ (see De Martino et al., 2005).

\subsection{Application of ICA to Stromboli seismic signals}

A first application of ICA to seismic signals was performed on explosion-quakes at Stromboli by Acernese et al. (2003, 2004). After synchronizing the seismic traces at all the stations in order to have instantaneous mixtures (the conditions required by standard linear ICA), the authors preliminarily applied PCA to reveal the internal structure of the data and explain the variance in the data. As shown in the left panel of Fig. 3, a few significant eigenvalues emerge from this analysis suggesting a few degrees of freedom underlying the dynamical system. Once the dimensionality of the data has been recognized, the authors applied ICA to check whether a decomposition was possible. 

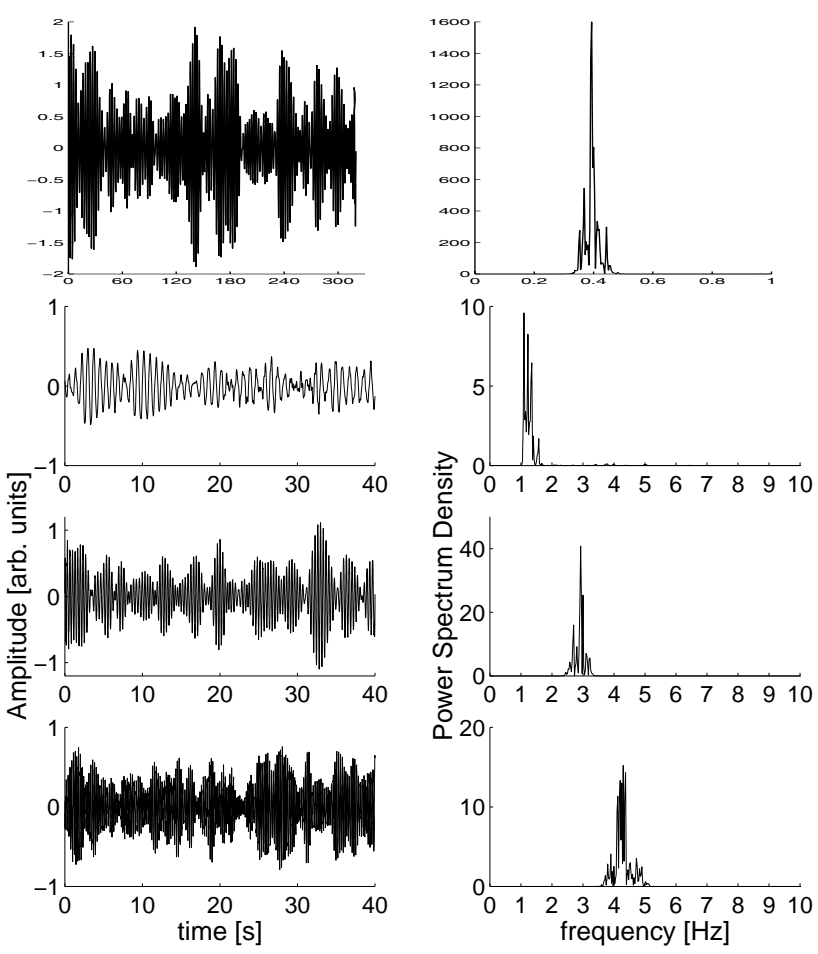

Fig. 4. ICA decomposition of Strombolian tremor: four independent signals are extracted with spectral content in the following ranges: [0.1-0.5], [0.8-1.5],[2-3.5], and [4-6] Hz (from De Lauro et al., 2005a, 2008).

In the panels on the right of Fig. 3, the results of the application of ICA are reported. As it can be seen, ICA decomposes the explosion-quake signals into three independent wave packets in the time domain, corresponding to well separated frequency bands $([0.8-1.5] \mathrm{Hz},[2-3.5] \mathrm{Hz}$, and $[4-6] \mathrm{Hz}$ ). Each band is characterized (in terms of polarization analysis) by body waves with particle motion pointing toward the crater area, even though the highest frequency band is affected by incoherent and signal-generated (scattering) noise (Acernese et al., 2004).

A similar decomposition was achieved for the volcanic tremor by De Lauro et al. (2008) and is reported in Fig. 4. They showed that the tremor is a linear superposition of four signals, which are self-oscillations produced by the coupling between magma-gas mixture and rock. The four signals are characterized by frequencies in specific ratios and with a clear radial polarization, which becomes more influenced by scattering going to the high frequencies. The lowest band $(0.1-0.5 \mathrm{~Hz})$ with a characteristic peak close to $0.3 \mathrm{~Hz}$ was studied by De Lauro et al. (2005a, 2006) who proved that it is the best polarized signal sometimes masked by contributions from oceanic noise.

Many authors (see, e.g. Godano and Capuano, 1999; Carniel and Di Cecca, 1999; De Martino et al., 2002b; De Lauro et al., 2008) have reconstructed the phase space

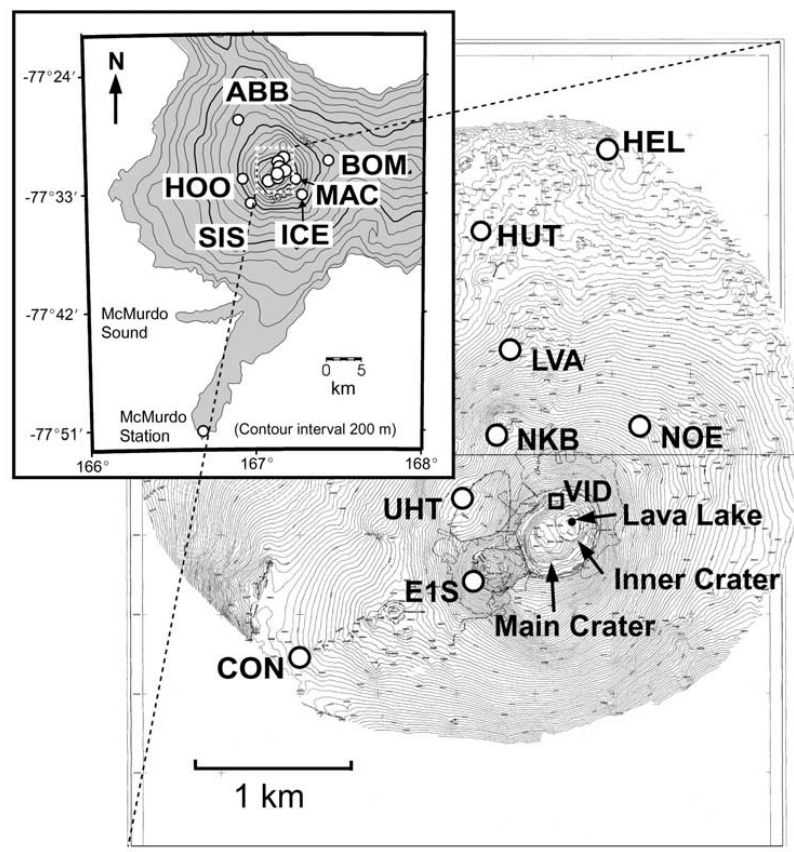

Fig. 5. Erebus, Ross Island (Antarctica): map of the volcano with the location of the permanent MEVO short-period and broadband seismic network, and the temporary PASSCAL deployments.

dynamics of explosions and tremor. They found low correlation dimensions in the range of [2.5-4.5], whereas the basic constituents of the signals have dimensions in the range [1-2]. Indeed, these decomposed ground vibrations can be reproduced in time and frequency domains by very simple systems of non-linear oscillators in the regime of selfoscillations (Konstantinou, 2002; De Lauro et al., 2008).

\subsection{Conclusions - Stromboli}

The application of ICA to Strombolian seismic signals demonstrated that tremor and explosions display not only a similar frequency content but also similar basic oscillations in the time domain with the only difference in the amplitude enhancement. In the theory of vibrating cavities, such as an organ pipe, these ICs have been associated with the vibration modes of the volcanic edifice (De Lauro et al., 2005b). In our case, the whole system vibrates at the fundamental frequency of $0.3 \mathrm{~Hz}$ and at the first three higher harmonics [0.81.5] Hz, [2-3.5] Hz, and [4-6] Hz. In this conceptual scheme, the fundamental/basic signal of Stromboli is the volcanic tremor expressing the transduction of continuous degassing of the volcano into ground motion, whereas the explosionquakes are just an amplitude enhancement of the tremor signal. The permanent gas flux produces cavity vibrations (tremor) only if there is a suitable impingement geometry (asperities/disomogenities) and, at low Reynolds numbers, the convective scales match the viscous ones (Villermaux and Hopfinger, 1994; Maurel et al., 1996). The permanent 

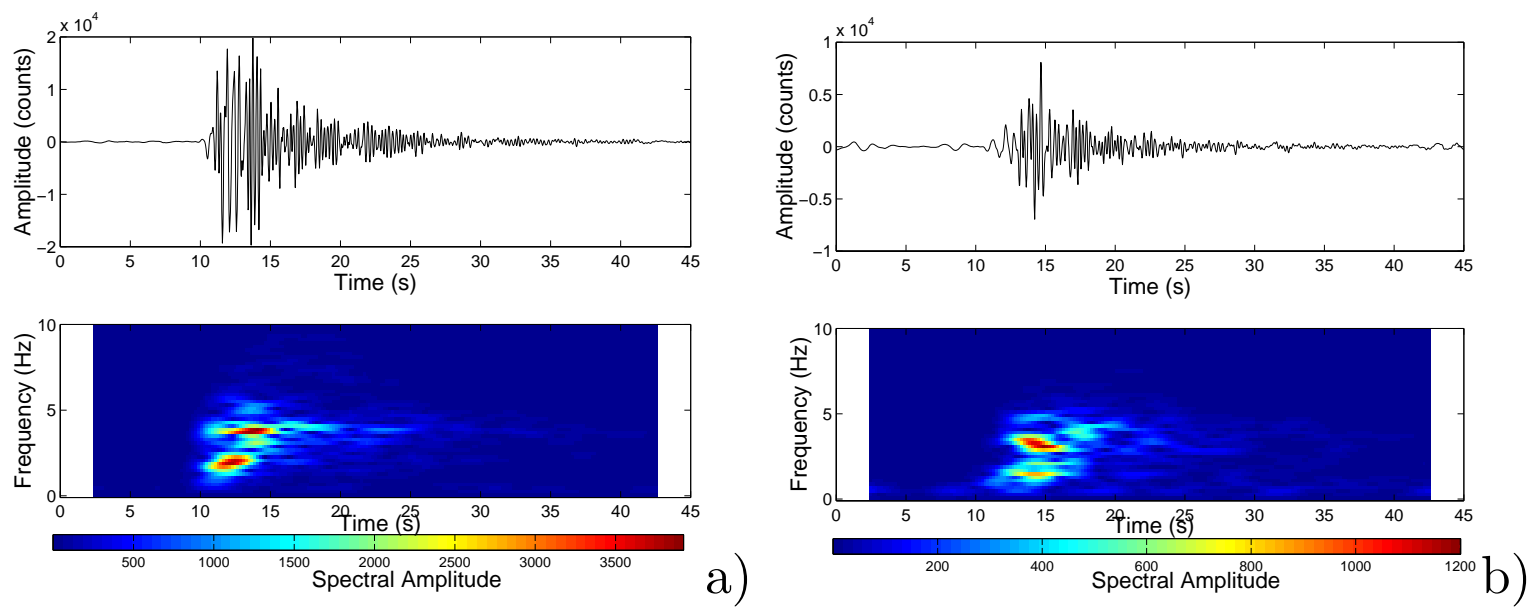

Fig. 6. Waveform and spectrogram of the radial component of the event (27/02/05 h, 23:40:24 UT) recorded at two stations located at (a) about $700 \mathrm{~m}(\mathrm{E} 1 \mathrm{~S})$ and (b) about $2 \mathrm{~km}(\mathrm{CON})$ from the lava lake. The spectrogram was estimated by Fast Fourier Transform (FFT) with a sliding Hanning window. It is extracted from De Lauro et al. (2009b). The 2 and $4 \mathrm{~Hz}$ main peaks in the spectrogram are shifted in time and the lower frequency $(2 \mathrm{~Hz})$ precedes the higher one $(4 \mathrm{~Hz})$ at E1S. No time delay is visible at CON. This might be related to dispersive effects.

degassing develops in an interface layer at about one kilometer depth, where suitable thermodynamic conditions of the temperature and pressure are fulfilled to let magma degas. Due to the low diffusion coefficient, the gas flow is confined within the interface layer, then it coalesces until buoyancy acts. Finally, the slug ascents rapidly, producing at the surface the observed explosions.

\section{Erebus}

The strato-volcano Erebus, $3794 \mathrm{~m}$ high, is located in Antarctica at the western boundary of the West Antarctic rift system, on Ross Island (see Fig. 5). The upper part of the magmatic system forms a lava lake with a radius of at present five meters (it has varied over the years up to $15 \mathrm{~m}$ ) (Aster et al., 2003). The activity of Erebus volcano is prevalently Strombolian and several explosions per day occur due to gas slugs of a few meters in radius, emerging at the lava lake as observed by video recordings (Aster et al., 2004; Dibble et al., 2008). Some explosions can occur also at other vents located near the lava lake, within the Inner Crater ( $80 \mathrm{~m}$ in radius) contained in turn within the Main Crater with a radius of $250 \mathrm{~m}$. In the last thirty years the activity of Erebus has also shown rare phreatic eruptions. In 1993, a strong explosion modified the morphology of the volcanic cone: a new crater appeared at south-west of the Inner Crater.

The regular rate of the explosive events is occasionally broken by the occurrence of swarms of explosions (up to 900 per day). Such episodes usually last several days and may be triggered by a slump of volcanic material (rock and ice) falling into the lava lake (Rowe et al., 2000). Furthermore, harmonic tremors have been episodically observed (Ruiz, 2003). They have been ascribed to volcanic degassing, or to the breaking of large icebergs.

Most efforts have focused on studying the very long period (VLP) signals preceding and following the explosions. VLP signals have been associated with the magma movements induced by gravity or inertial forces which follow slug ascent, eruption and recharge of the lava lake, even if the details of this process are not yet well known (Rowe et al., 1998; Aster et al., 2003).

Recently, the high-frequency seismic wavefield $(>0.5 \mathrm{~Hz})$ has been analyzed, filling a gap in the study of this volcano. In details, De Lauro et al. (2009a) have properly decomposed the seismic signals of Erebus by ICA, getting also information on their source origin.

\subsection{Spectral analysis}

Explosion-quakes associated with the bursting of gas slugs at the lava lake have been studied. After frequency filtering the raw seismic series to discard the contributions lower than $1 \mathrm{~Hz}$ and isolate the high-frequency signals, De Lauro et al. (2009b) detected more than one class of events on the basis of cross-correlation analysis corresponding to different eruptive vents. Among these, the events selected for the highfrequency analysis have been chosen as those of the most populated class on the basis of their signal-to-noise ratio. Moreover, these events are produced by a very stable source mechanism. Indeed, they preserve the waveforms over the years as supported by a correlation coefficient greater than 0.8 (De Lauro et al., 2009b). The high-frequency energy of the explosions is mainly concentrated in the frequency range 
$1-8 \mathrm{~Hz}$ (see, e.g. Rowe et al., 2000), but a variety of spectra can be distinguished (De Lauro et al., 2009a). An example of spectrogram analysis performed on a representative event recorded at two sensors (E1S, CON), located $704 \mathrm{~m}$ and $2 \mathrm{~km}$ from the lava lake, respectively, is given in Fig. 6.

\subsection{Application of ICA to Erebus seismic signals}

We show the results of the application of the FastICA algorithm to eight high-pass filtered explosion-quakes as reported in De Lauro et al. (2009a). The authors considered these events as mixtures, which are different realizations of the same stable source mechanism. The traces were aligned maximizing the cross-correlation function. The seismograms relative to the same component of the motion are very similar, while differences arise between the waveforms in the orthogonal directions. Introducing in the same mixture matrix the signals of the three directions of the motion implies that no constriction is imposed on the polarization of the extracted components. In other words, the ICs may be more visible in one component of the motion.

Figure 7 shows the results of PCA, indicating that $80 \%$ of information is associated with the first three eigenvalues, thus providing an estimate of the number of ICs. Therefore, the number of the mixtures guarantees that all unknown ICs can be extracted. In line with the PCA results, three independent signals, well-defined in waveforms and spectra, have been recognized (see Fig. 8). These signals are characterized by a very peculiar spectral content. Indeed, their spectra are peaked at $2 \mathrm{~Hz}, 3 \mathrm{~Hz}$, and $4 \mathrm{~Hz}$, respectively. The independent signal peaked at $2 \mathrm{~Hz}$ displays the highest amplitude in the first $5 \mathrm{~s}$. The other ICs have a smoother behavior, but the largest part of energy is emitted during the first seconds. The results of ICA are independent of the choice of the sensor, and the extracted ICs can be attributed to a common physical source mechanism inducing vibrations. De Lauro et al. (2009a) demonstrated that for the three ICs, a clear radial polarization with high coefficients of rectilinearity is recognized, indicating the propagation of body waves crossing the seismic stations, although for the stations furthest from the lava lake another direction is superimposed, which was interpreted by the authors assuming an external source in the direction of the polarization, or as due to local topographic effects such as dykes, joints, etc.

In conclusion, the experimental signals associated with the explosion-quakes at Erebus volcano in the high-frequency band are a linear superimposition of three component signals. The decomposition is similar to that achieved for Stromboli and as in that case it is possible to infer some information on the complexity (e.g. degrees of freedom) of the underlying dynamical system. The reconstruction of the asymptotic dynamics in a suitable phase space provides an estimate of the phase-space dimensions. The recorded signals display fractal dimensions in the range of [2.8-3.2] evidencing a non-linear behaviour of the generating system (De Lauro et al., 2009a).
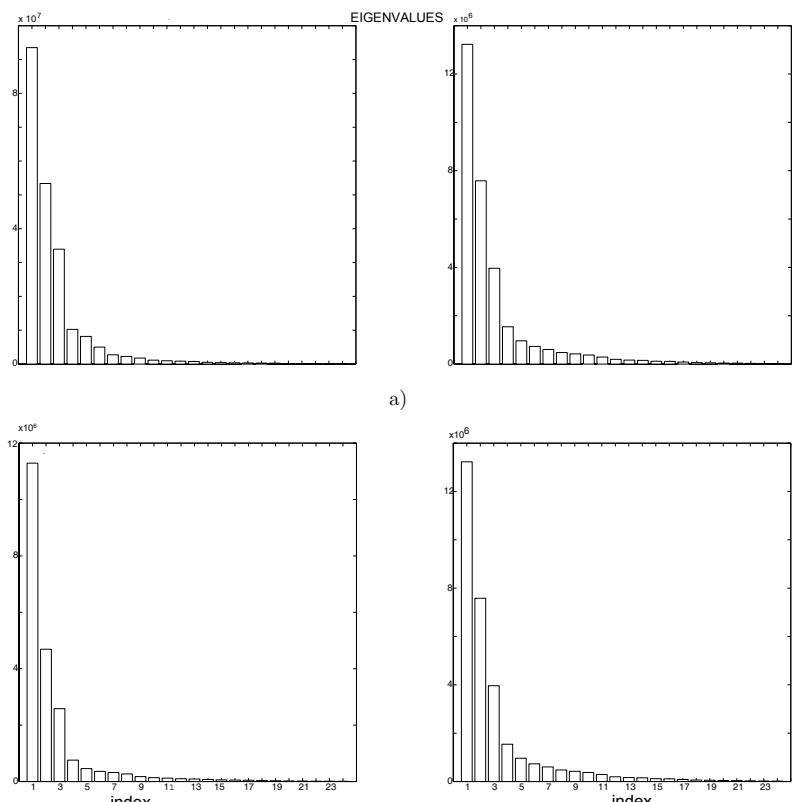

Fig. 7. PCA results: Eigenvalues relative to the signals of the four stations composing the seismic network (from De Lauro et al., 2009a): (a) E1S; (b) NKB; (c) CON; (d) LEH. The first three eigenvalues retain the $84 \%, 80 \%, 86 \%$, and $75 \%$ of information at each respective station.

This is another analogy with the explosion-quakes at Stromboli (see, e.g. De Lauro et al., 2008 and references therein). The details of the decomposition and of the estimation of the fractal dimensions do not perfectly match for Stromboli and Erebus, suggesting that although an overall common source mechanism can be detected, at Erebus more complex vibrating structures are involved.

\subsection{Conclusions - Erebus}

The decomposition of ground vibrations by ICA has strong analogies with the extraction of Landau modes (selfoscillations) in the mechanical and acoustical vibration fields in the organ pipe (De Lauro et al., 2007) as it was the case for Stromboli. On the basis of this analogy, De Lauro et al. (2009a) conjectured the existence of a main conduit vibrating in the second Landau mode with frequencies of 2 and $4 \mathrm{~Hz}$, localized under the lava lake. In addition, they ascribed the $3 \mathrm{~Hz}$ mode to another conduit near the lava lake (e.g. fumaroles) whose vibration is induced by the oscillations of the main conduit in agreement with other studies (see, e.g. Johnson et al., 2008). Such a phenomenon is known as "modified Mitnahme effect" in organ pipe literature (Abel et al., 2006): a played pipe is sensitive to the presence of another pipe even silent. In this conceptual scheme, this shorter conduit $(3 \mathrm{~Hz})$ is the silent pipe whereas the played pipe is the longer conduit $(2$ and $4 \mathrm{~Hz})$ under the lava lake. However, the number and the position of seismic stations presently installed do not allow a suitable localization of the additional conduit. 
E. De Lauro et al.: A comparison among self-sustained vibrations in volcanic areas
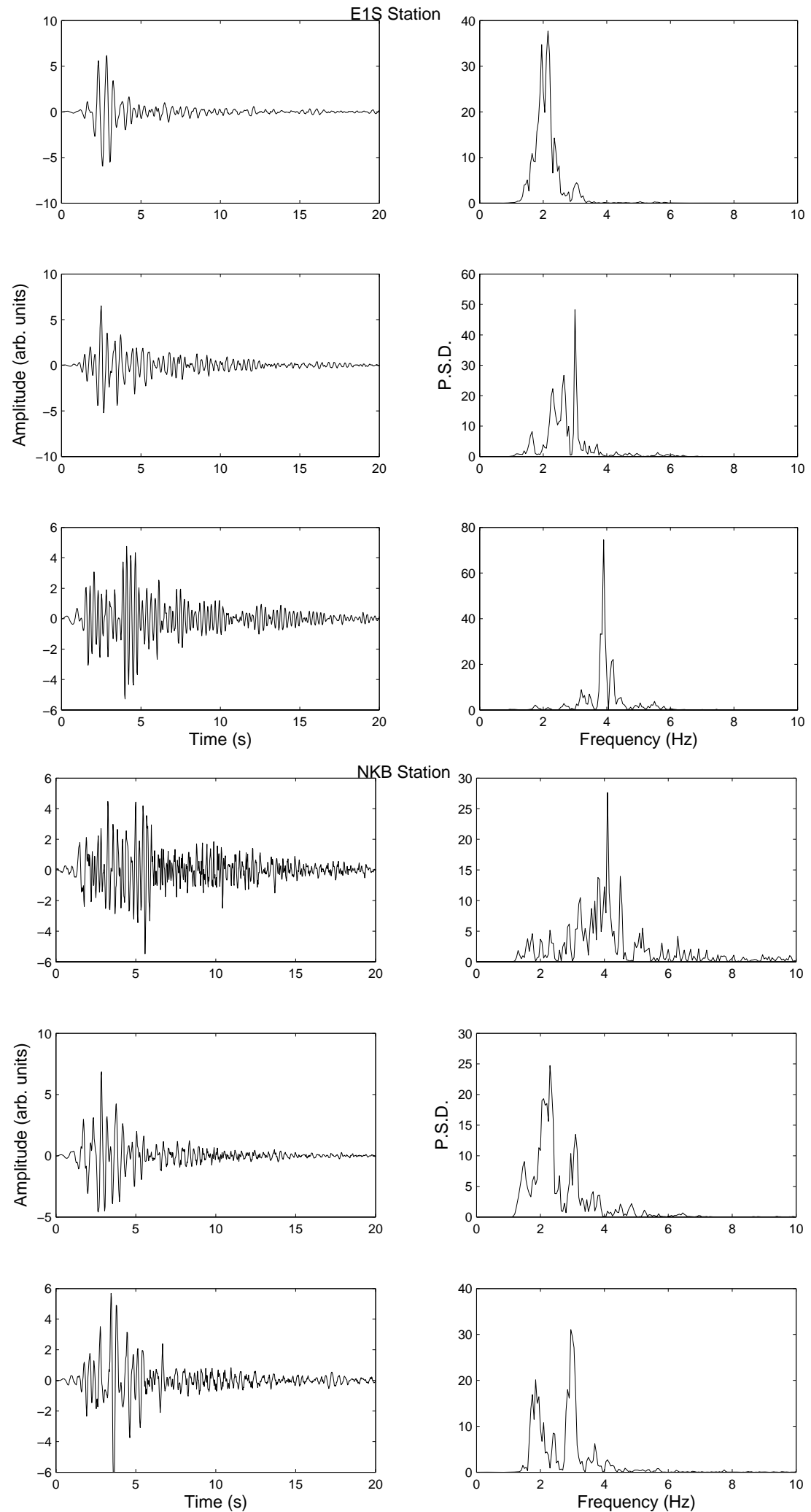

Fig. 8. Independent signals extracted by ICA in time domain and relative frequency content considering the recordings of the two stations closest to the lava lake (from De Lauro et al., 2009a). 


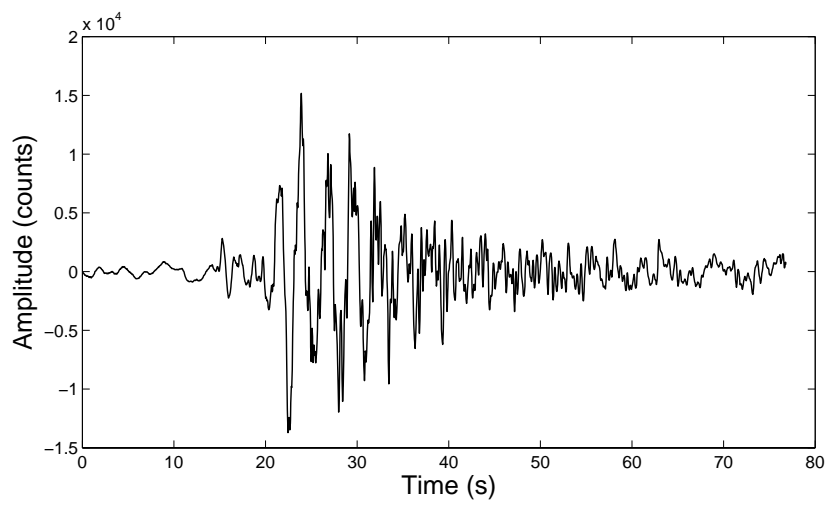

Fig. 9. An example of Colima LP events (2006/01/22 h 00.13.44 vertical component).

\section{Volcán de Colima}

Volcán de Colima is an andesitic stratovolcano located within the Colima graben at the western part of the Mexican Volcanic Belt. It is one of the most active volcanoes of North America and surely the most dangerous one of Mexico. It forms with Nevado de Colima, which is older and inactive, the Colima Volcanic Complex. Its activity is characterized by eruptive cycles consisting of the extrusion of lava flow followed by the growth of a lava dome and its subsequent destruction accompanied by large explosions. It shows a wide range of eruption styles, like dome growth, lava flow accompanied by frequent small block avalanches, phreatic explosions, explosive events and pyroclastic flows (Bretón Gonzáles et al., 2002; Luhr, 2002). The recent activity started at the end of the 1990s and in autumn of 2004 the third extrusive episode of this eruption began. This activity was accompanied by intermittent explosive activity, represented mainly by Vulcanian-style explosions, during which streams of vapour and ash were emitted (Zobin et al., 2006). Each Vulcanian-style explosion is introduced about one minute before by a seismic event lasting about $30 \mathrm{~s}$ and having a frequency content in the range of $(0.3-4) \mathrm{Hz}$ (see Fig. 9). This event has been associated with pressurization phenomena occurring within the volcanic plumbing system and has been labeled as a Long-Period (LP) event (Zobin et al., 2006; Palo et al., 2009; De Lauro et al., 2011).

\subsection{Spectral analysis}

ICA has been applied to both background seismic signals (Cusano and Palo, 2011) and 20 LPs (De Lauro et al., 2011). In all the cases, the recordings were acquired by four threecomponent broad-band seismometers (Lennartz LE-3D/20s) which have monitored Colima volcano from November 2005 to May 2006 (see the report of the survey at http://www.ov. ingv.it/italiano/pubblicazioni/openfile/07_07.htm). The instruments were labeled as COCA, COME, COBA, COTE

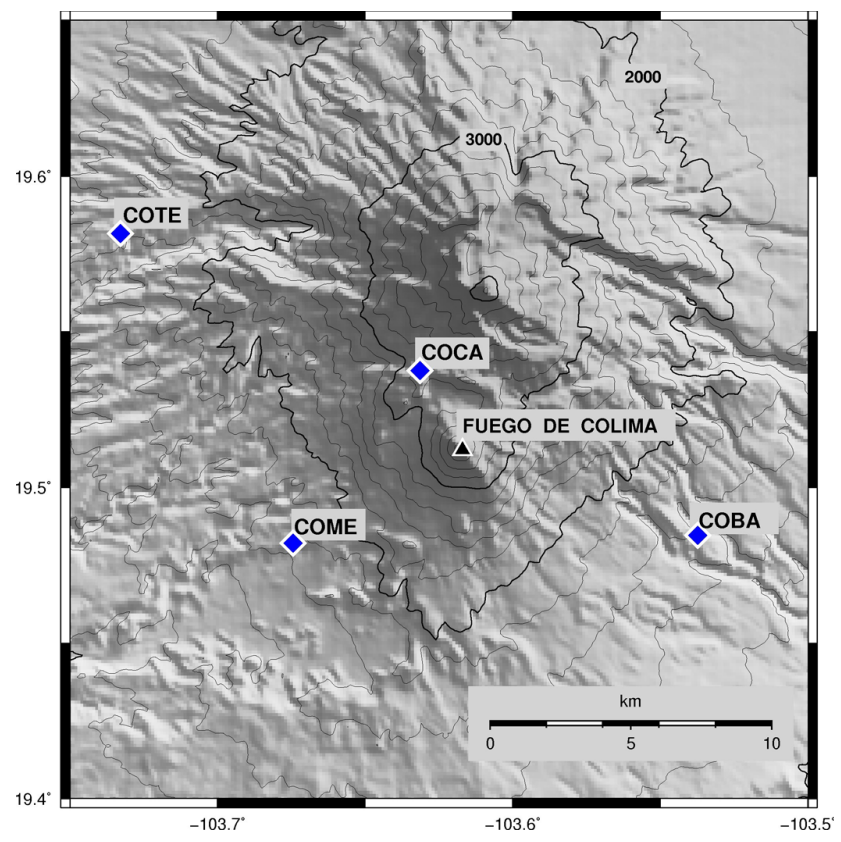

Fig. 10. Position of the seismic sensors at the Colima volcano. The black triangle indicates the crater area.

(sorted by crater-station distance, which spans the range 3.214.4 km, Fig. 10).

Early works on LP events (recorded by short-period seismometers) indicated a predominance of frequencies in the range [1-2] Hz (Zobin et al., 2006; Palo et al., 2009). Recently, Fourier analysis of LP events recorded by broad-band instruments showed spectra with a decreasing envelope and sharp peaks, with the highest one at $[0.4-0.5] \mathrm{Hz}$ at all the stations (Fig. 11) (De Lauro et al., 2011). The other peaks correspond to nearly integer multiples of this common frequency, which is thus interpreted as the fundamental vibration mode of a resonant structure. The frequency of the higher modes slightly changes with the station. In details, COCA and COME share the same spectral peaks, although the peaks of the two highest modes are well distinguishable only at COCA. Similarly, COBA and COTE share the same peaks except for that of the highest mode, which is not visible at COBA. Hence, the spectra indicate the existence of vibration modes that change depending on the distance from the crater. A slight decrease of the frequencies moving from the near-field to the far-field suggests the presence of different resonant structures involved. In all cases, the decreasing envelope is preserved. Actually, another peak is present at about $0.1-0.2 \mathrm{~Hz}$, but it is not induced by volcanic activity and is the effect of the oceanic microseismic noise. Indeed, its amplitude is nearly independent of the crater-station distance.

The background seismic signal contains prevalently two spectral peaks common to all stations, located respectively close to $0.15 \mathrm{~Hz}$ and $0.3 \mathrm{~Hz}$ (Fig. 12b), with the former 

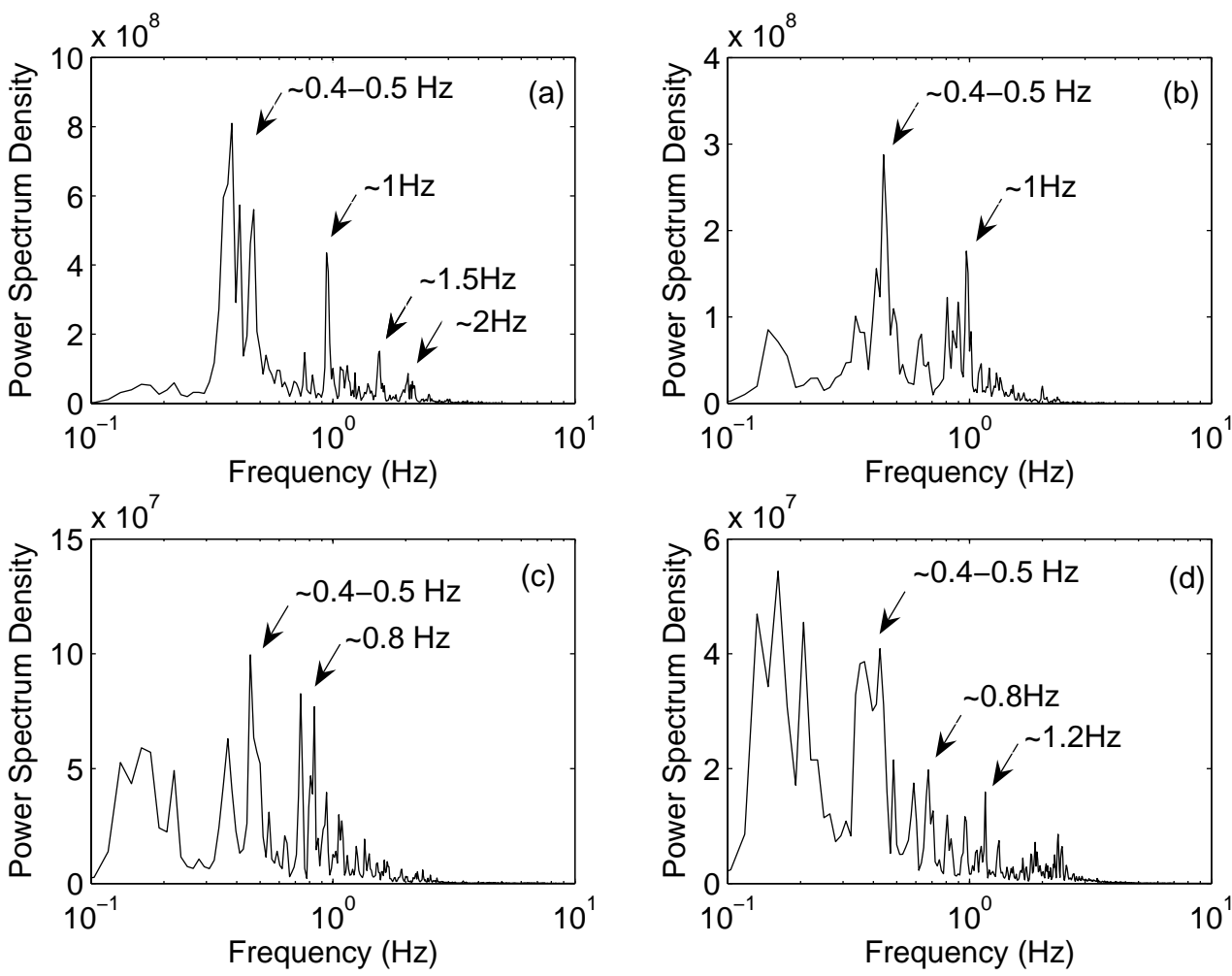

Fig. 11. Stacked power spectrum of LP events of Colima volcano at (a) COCA, (b) COME, (c) COBA, (d) COTE (from De Lauro et al., 2011). The $\mathrm{x}$-axis is in log-scale. Arrows highlight the principal peaks.

generally higher than the latter (Cusano and Palo, 2011). Nevertheless, the amplitude of these peaks is variable and during some time periods the latter spectral peak becomes dominant (Fig. 12a).

\subsection{Application of ICA to Colima seismic signals}

De Lauro et al. (2011) have shown that the application of PCA to LP events indicates that at most three eigenvalues are significant: the principal components contain from $54 \%$ to $74 \%$ of the information depending on the station and this quantity increases moving towards the crater.

For the application of ICA in this case, the authors consider as mixture all the LP events at each station, on the basis of the hypothesis of a non-destructive and repetitive source. ICs extracted from the LP events are well distinguished in time and spectral domains (Fig. 13). As the spectral properties of the LP events, the features of the ICs depend on the crater-station distance. Indeed, COCA and COME display similar ICs and the same happens for COBA and COTE. In detail, the ICs in near-field (approximately limited by the position of COME) are peaked close to $0.5 \mathrm{~Hz}$ and $1 \mathrm{~Hz}$, respectively (and also at $1.5 \mathrm{~Hz}$ at COCA), whereas they are peaked close to $0.4 \mathrm{~Hz}$ and $0.8 \mathrm{~Hz}$ (and $1.2 \mathrm{~Hz}$ at COBA) in far-field (De Lauro et al., 2011). Thus, ICA identifies ground oscillations with two or three characteristic time-scales linearly mixed in the LP events.
The polarization properties of the ICs of the LP events confirm the dependence of the seismic wavefield on the distance from the crater. Indeed, in near-field the direction of the polarization vector of all the ICs is radial, i.e. pointing to the crater, whereas in far-field this direction is orthogonal. The angle that the polarization vector forms with the NS-EW plane in all cases is lower than 20 degrees, reflecting shallow ground oscillations (De Lauro et al., 2011). This complex polarization pattern extends the results of Palo et al. (2009) who found compressive waves for the first $10-15 \mathrm{~s}$ of the LP events recorded by a short-period seismometer located $4.5 \mathrm{~km}$ from the crater, i.e. in the near-field whose boundary can be fixed coincident with the position of COME station $(6.9 \mathrm{~km}$ far from the crater) or farther.

The dynamical system associated with the ICs extracted from LP events has been reconstructed by De Lauro et al. (2011). All ICs have fractal dimensions ranging between 1 and 2, suggesting that the basic constituents of the seismic wavefield are produced by deterministic and non-linear dynamic systems of low dimensionality, which can de identified with self-sustained oscillations. The superposition of the ICs produces the raw signals that, indeed, have a (noninteger) dimension lower than four.

Two ICs are extracted from the background signal retaining about the $60 \%$ of the information (Cusano and Palo, 2011). They are nearly monochromatic signals with frequency peaks respectively at about $0.15 \mathrm{~Hz}$ and $0.3 \mathrm{~Hz}$, 


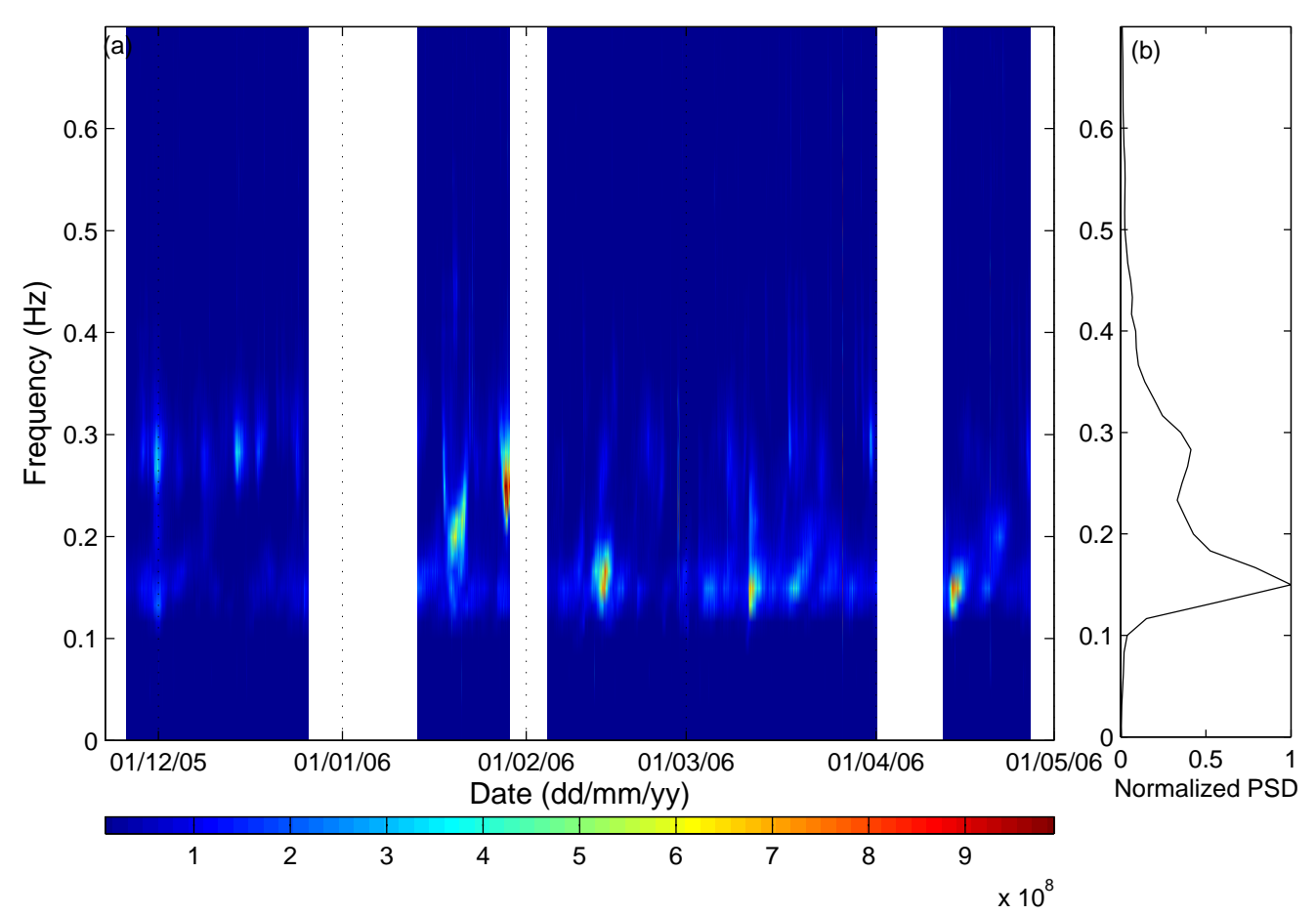

Fig. 12. (a) Spectrogram of the background seismic signal of the Colima volcano between 0.1 and $0.5 \mathrm{~Hz}$. (b) Mean normalized power spectra obtained by averaging the spectra computed from $60 \mathrm{~s}$ time-windows over the complete data-set and dividing by the maximum value. The figure is contained in Cusano and Palo (2011).
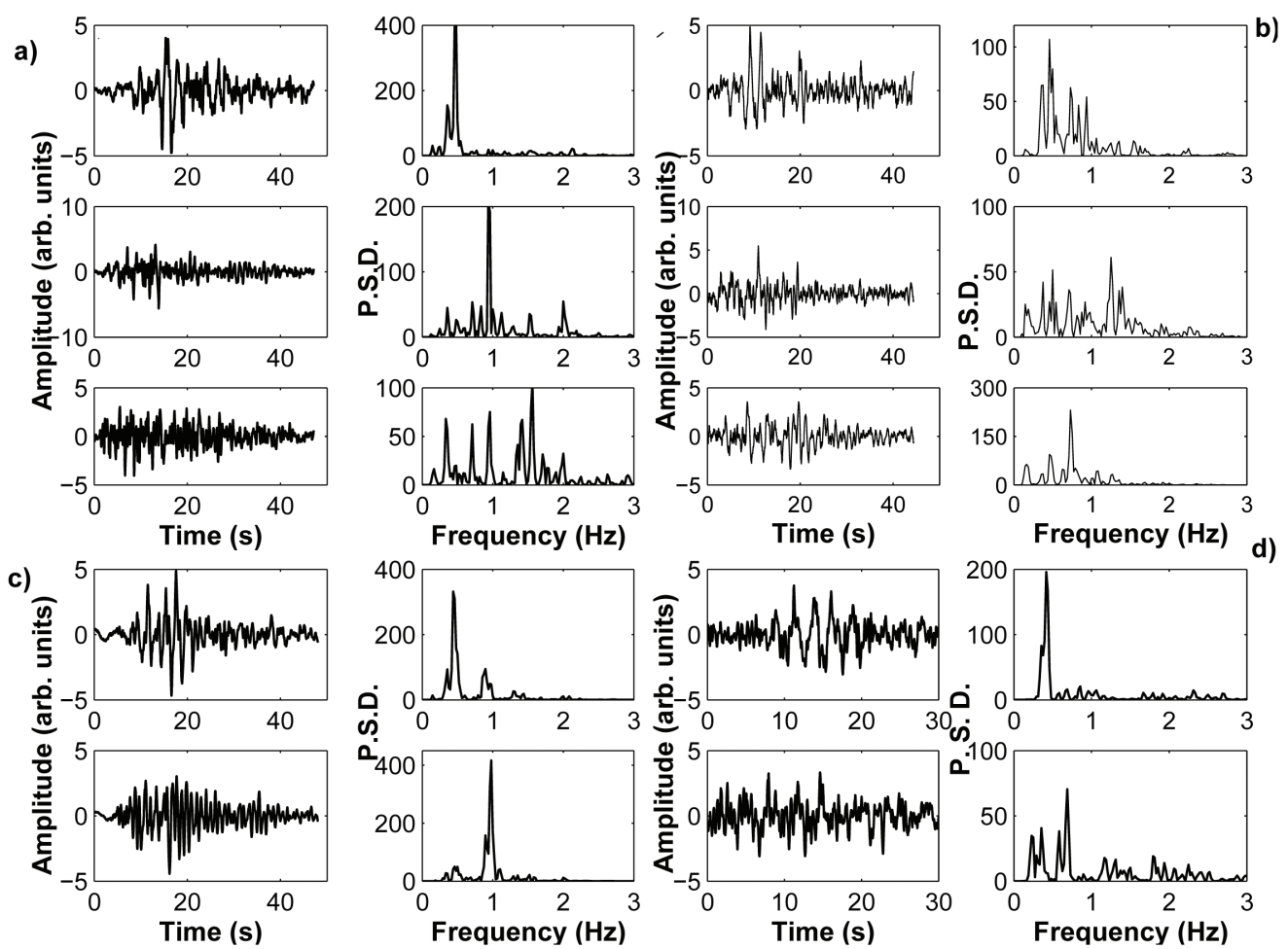

Fig. 13. Independent components of Colima LP events in time and frequency domain at the four stations (COCA (a), COBA (b), COME (c), COTE (d)). Figure extracted from De Lauro et al. (2011). 

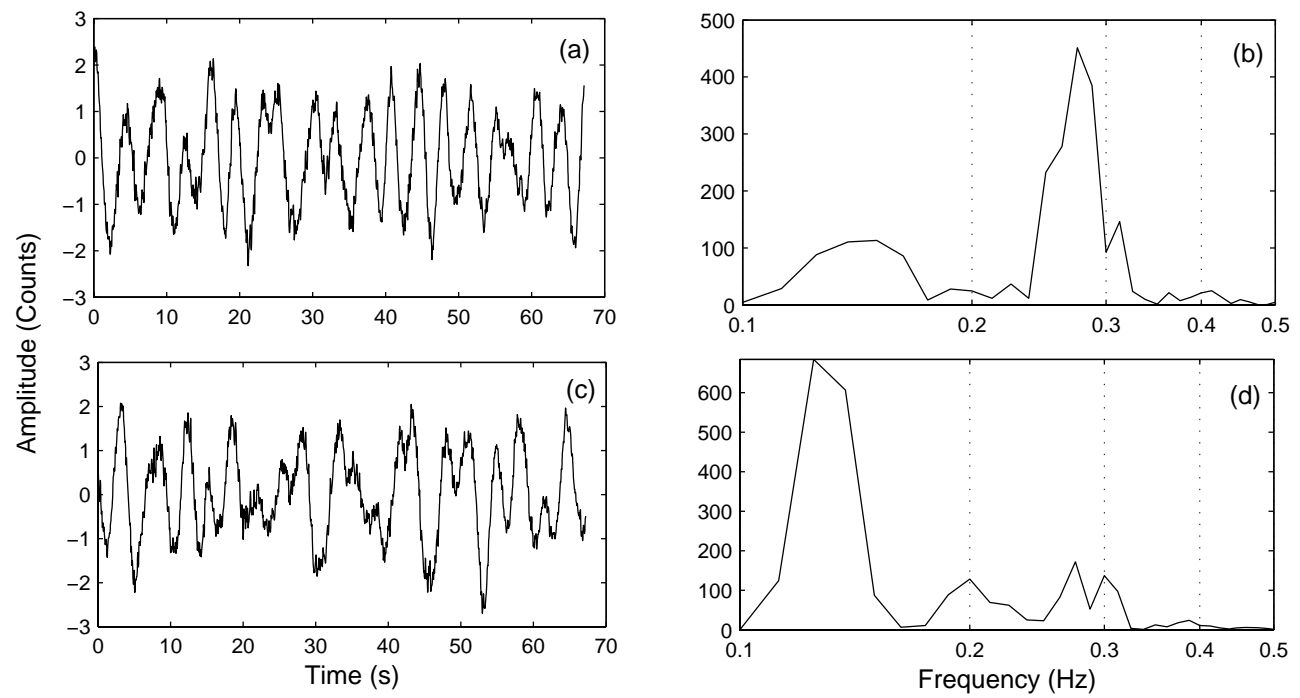

Fig. 14. Independent components of the Colima background seismic signal in time (a, c) and frequency (b, d) domain (from Cusano and Palo, 2011).

suggesting that the spectral content of the background seismic signal is the effect of the superposition of independent signals (Fig. 14). The amplitude of the ICs is variable and mainly follows the behavior of the two principal spectral peaks. In detail, the IC peaked at $0.15 \mathrm{~Hz}$ is generally more energetic, except for a time interval of about 20 days when this behavior is reversed.

Wavefield reconstruction of the two ICs of the background signal indicates a strong influence of the oceanic microseismic noise. Indeed, in the far-field both ICs are mainly composed of shallow waves incoming from the SW direction, i.e. from the Pacific Ocean coast. On the other hand, in the nearfield there is also an imprint of volcanic tremor on the IC peaked at $0.3 \mathrm{~Hz}$ that induces waves coming from the crater area and a polarization vector pointing towards the crater.

\subsection{Conclusions - Colima}

De Lauro et al. (2011) indicate that LP events of Colima volcano are the superposition of a few basic constituents that are non-linear signals produced by dynamical systems of low dimensionality identified with self-sustained oscillators. Given the nearly integer ratios between the mean frequencies of the ICs and of the main spectral peaks, these basic constituents are interpreted as the vibration modes of a suitable volcanic structure, whose fundamental mode is peaked at about 0.4 $0.5 \mathrm{~Hz}$. Moreover, the frequency and the energy of the modes (which, in a first approximation, can be estimated from the power spectra) suggest a very simple geometry of the structure. Indeed, monotonically decreasing spectra are associated with vibrations of cylindrically-symmetric cavities interacting with a fluid flow. In this framework, the frequency of the lowest mode can be used to estimate the linear dimensions of the vibrating structure (eventually coincident with the principal conduit). Indeed, within the approximation of linear resonance and adopting a standing-wave velocity of $\sim 1 \mathrm{~km} \mathrm{~s}^{-1}$, the authors estimate a length of $\sim 1 \mathrm{~km}$ (using $0.5 \mathrm{~Hz}$ as the frequency of the lowest mode and considering an open-ends vibrating structure), in line with other estimates of the source position (Petrosino et al., 2011).

On the basis of the pattern of polarization and ICA results, De Lauro et al. (2011) propose the existence of a branched plumbing system consisting of two main (approximately cylindric) conduits directed along quasi-orthogonal directions. In detail, the principal (vertical) conduit at suitable height $(\sim 1 \mathrm{~km})$ would appear separated in a sub-horizontal side branch directed along the North-West/South-East direction, in which magma intrusion generates wall oscillations directed transversally with respect to the crater area. The direction of this hypothesized structure is coincident with the main direction of the extensional axis of the stress field of the area, which, in turn, individuates the direction along which the Colima volcano complex has experienced gravitational collapses (Garduño-Monroy et al., 1998). A similar structure has also been conjectured by Domínguez et al. (2001), who imaged a branched plumbing system induced by crack propagation. A branched plumbing system can also explain the particular ejective nature of Vulcanian and ash-free events of Volcán de Colima, characterized by a seismic phase without emission followed within few tens of seconds by the real eruption. In the background signal, two different sources in the independent component at $0.3 \mathrm{~Hz}$ coexist in near-field: the volcanic source signal is more evident whenever the energy of the independent component peaked at $0.15 \mathrm{~Hz}$ decreases, that is when the intensity of the microseismic noise lowers allowing the emergence of a low-energy volcanic signal (Cusano and Palo, 2011). 


\section{Discussion}

For all three volcanoes ICA decomposition allows to recognize that seismological signals are self-coherent oscillations. Of course, the characteristic vibration time scales depend on the local geometry of the volcanic edifice and rheological properties.

The seismic wavefield reconstruction by means of nonlinear techniques allows to depict a common framework for the explosive mechanisms of low- and medium-energy and repetitive eruptive volcanism, independently of the nature of the magma involved. Indeed, also at the andesitic Colima volcano, explosive eruptions are an enhancement of the magma-gas mixture flux arising along the conduit, whereas in the basic state the permanent degassing is responsible for the volcanic tremor, as occurs for basaltic volcanoes.

In all cases, the seismic signals are a direct effect of the interaction between the magma-gas flux and the conduit, which induces a coherent vibration of the rock in the form of a superposition of non-linear vibration modes. Hence, the suitable decomposition of the seismic wavefield of active volcanoes throws light on the geometry of the plumbing systems and on the excitation mechanisms. In this scheme, volcanic tremor and explosive events are both the vibrations of a suitable volcanic cavity, but they are effects of magmatic fluid jets of different intensities.

The principal distinction between the basaltic and andesitic cases can be identified in the difference of the magmagas flux between the basic state and the explosive events. In other words, the high viscosity of the andesitic magmas reduces the permanent degassing, thus producing a low-energy volcanic signal (volcanic tremor) and inhibiting higher vibration modes, whereas the explosions are induced by strong emission of magmatic fluids, whose ascent along the conduit produces Vulcanian-style eruptions and the excitation of several vibration modes.

On the other hand, in the Strombolian-like regime, the permanent gas flux is of the same order of magnitude as that during the explosions. It means that the flux of dispersed gas particles exsolving and arising in the magma (inducing the tremor) and the flux of coherent gas slugs (inducing the explosions) have similar magnitude. Such comparable fluxes imply a very similar seismic wavefield for volcanic tremor and explosions, with the only difference in amplitude.

Edited by: R. Donner

Reviewed by: J. Heitzig and three other anonymous referees

\section{References}

Abel, M., Bergweiler, S., and Gerhard-Multhaupt, R.: Synchronization of organ pipes by means of air flow coupling: experimental observations and modeling, J. Acoust. Soc. Am., 119, $2467-$ 2475, 2006.

Acernese, F., Ciaramella, A., De Martino, S., De Rosa, R., Falanga, M., and Tagliaferri, R.: Neural networks for blind-source separation of Stromboli explosion quakes, IEEE Trans. Neural Networks 14, 167-175, 2003.

Acernese, F., Ciaramella, A., De Martino, S., Falanga, M., Godano, C., and Tagliaferri, R.: Polarisation analysis of the independent components of low frequency events at Stromboli volcano (Eolian Islands, Italy), J. Volcanol. Geotherm. Res., 137, 153-168, 2004.

Andronov, A. A., Vitt, A. A., and Khaikin, S. E.: Theory of oscillators, Dover Publication Inc., New York, 1966.

Aster, R., Mah, S., Kyle, P., McIntosh, W., Dunbar, N., Johnson, J., Ruiz, M., and McNamara, S.: Very long period oscillations of Mount Erebus Volcano, J. Geophys. Res., 108, B11, 2522, 2003.

Aster, R., Mcintosh, W., Kyle, P., Esser, R., Bartel, B., Dunbar, N., Jones, B., Johnson, J., Karstens, R., Kurnik, C., Mcgowan, M., Mcnamara, S., Meertens, C., Pauly, B., Richmond, M., and Ruiz, M.: Real-time Data received from Mount Erebus volcano, Antarctica, EOS, 85, 97-104, 2004.

Balmforth, N. J., Craster, R. V., and Rust, A. C.: Instability in flow through elastic conduits and volcanic tremor, J. Fluid Mech., 527 353-377, 2005.

Bottiglieri, M., De Martino, S., Falanga, M., Godano, C., and Palo, M.: Statistics of inter-time of Strombolian explosion-quakes, Europhys. Lett., 72, 493-498, 2005.

Bretón Gonzáles, M., Ramirez, J. J., and Navarro, C.: Summary of the historical eruptive activity of Volcán de Colima, Mexico 1519-2000, J. Volc. Geotherm. Res., 117, 21-46, 2002.

Cabras, G., Carniel, R., and Wassermann, J.: Blind source separation: An application to the mt. Merapi volcano, Indonesia, Fluct. Noise Lett., 8, 249-260, 2008.

Cabras, G., Carniel, R., and Wassermann, J.: Signal enhancement with generalized ICA applied to mt. Etna volcano, Italy, Bollettino di Geofisica Teorica ed Applicata, 51, 57-73, 2010.

Carniel, R. and Di Cecca, M.: Dynamical tools for the analysis of long term evolution of volcanic tremor at Stromboli, Ann. Geofis., 42, 483-495, 1999.

Chouet, B. A., Saccorotti, G., Martini, M., Dawson, P., De Luca, G., Milana, G., and Scarpa, R.: Source and path effect in wave field of tremor and explosions at Stromboli Volcano, Italy, J. Geophys. Res., 102, 15129-15150, 1997.

Chouet, B. A., Dawson, P., Ohminato, T., Martini, M., Saccorotti, G., Giudicepietro, F., De Luca, G., Milana, G., and Scarpa, R.: Source mechanisms of explosions at Stromboli Volcano, Italy, determined from moment-tensor inversions of very-long-period data, J. Geophys. Res., 108, 2019, doi:10.1029/2002JB001919, 2003.

Ciaramella, A., De Lauro, E., De Martino, S., Di Lieto, B., Falanga, M., and Tagliaferri, R.: Characterization of Strombolian events by using independent component analysis, Nonlin. Processes Geophys., 11, 453-461, doi:10.5194/npg-11-453-2004, 2004.

Ciramella, A., De Lauro, E., De Martino, S., Falanga M., and Tagliaferri, R.: Ica based identification of dynamical systems generating synthetics and real world time series, Soft Comput., 10, 
587-606, 2006.

Ciaramella, A., De Lauro, E., Falanga, M. and Petrosino, S.: Automatic detection of long-period events at Campi Flegrei Caldera (Italy), Geophys. Res. Lett., 38, L18302, doi:10.1029/2011GL049065, 2011.

Cuomo, V., De Martino, S., Falanga, M., and Mona, L.: Influence of local dust source and stochastic fluctuations on Saharan aerosol index dynamics, Int. Journ. Mod. Phys. B, 23, 5383-5390, 2009.

Cusano, P. and Palo, M.: Wavefield analysis of the background seismic signal at Volcán de Colima, México, in review, Geophys. J. Intern., 2011.

De Lauro, E., De Martino, S., Falanga, M., Palo, M., and Scarpa, R.: Evidence of VLP volcanic tremor in the band [0.2-0.5] Hz at Stromboli volcano, Italy, Geophys. Res. Lett., 32, L17303, doi:10.1029/2005GL023466, 2005a.

De Lauro, E., De Martino, S., Falanga, M., Ciaramella, A., and Tagliaferri, R.: Complexity of time series associated to dynamical systems inferred from independent component analysis, Phys. Rev. E, 72, 046712, doi:10.1103/PhysRevE.72.046712, 2005b.

De Lauro, E., De Martino, S., Falanga, M., and Palo, M.: Statistical analysis of Stromboli VLP tremor in the band [0.1-0.5] Hz: some consequences for vibrating structures, Nonlin. Processes Geophys., 13, 393-400, doi:10.5194/npg-13-393-2006, 2006.

De Lauro, E., De Martino, S., Esposito, E., Falanga, M., and Tomasini, E. P.: Analogical model for mechanical vibrations in flue organ pipes inferred by independent component analysis, J. Acoust Soc. Am., 122, 2413-24, 2007.

De Lauro, E., De Martino, S., Del Pezzo, E., Falanga, M., Palo, M., and Scarpa, R.: Model for high-frequency Strombolian tremor inferred by wavefield decomposition and reconstruction of asymptotic dynamics, J. Geophys. Res., 113, B02302, 2008.

De Lauro, E., De Martino, S., Falanga, M., and Palo, M.: Decomposition of high-frequency seismic wavefield of the Strombolianlike explosions at Erebus volcano by Independent Component Analysis, Geophys. J. Int., 177, 1399-1406, 2009a.

De Lauro, E., De Martino, S., Falanga, M., and Palo, M.: Modelling the macroscopic behavior of Strombolian explosions at Erebus volcano, Phys. Earth Planet. In., 176, 174-186, 2009b.

De Lauro, E., De Martino, S., Falanga, M., and Ixaru, L. Gr.: Limit cycles in nonlinear excitation of clusters of classical oscillators, Comput. Phys. Commun., 180, 1832-1838, 2009c.

De Lauro, E., De Martino, S., Palo M., and Ibañez, J. M.: Self-sustained oscillations at Volcán de Colima (México) inferred by Independent Component Analysis, Bull. Volc., doi:10.1007/s00445-011-0520-x, 10 August 2011.

Del Pezzo, E., Godano, C., Gorini, A., and Martini, M.: Wave polarization and location of the source of the explosion quakes at Stromboli Volcano, in: IAVCEI Proc. Volcanology, edited by: Gasparini, P., Scarpa, R., and Aki, K., Berlin: Springer-Verlag, 3, 279-295, 1992.

De Martino, S., Falanga, M., and Mona, L.: Stochastic Resonance Mechanism in Aerosol Index Dynamics, Phys. Rev. Lett., 89, 128501, doi:10.1103/PhysRevLett.89.128501, 2002a.

De Martino, S., Godano, C., and Falanga, M.: Self-sustained oscillator as a model for explosion quakes at Stromboli Volcano, Nonlin. Processes Geophys., 9, 31-35, doi:10.5194/npg-9-31-2002, 2002b.

De Martino, S., Falanga, M., Scarpa, R., and Godano, C.: Very long period volcanic tremor at Stromboli, Italy, Bull. Seismol. Soc. Am., 95, 1186-1192, 2005.

De Martino, S., Falanga, M., Palo, M., Montalto, M., and Patanè, D.: Statistical analysis of the seismicity during the Strombolian crisis of 2007, Italy: evidence of a precursor in tidal range, J. Geophys. Res., 116, B09312, doi:10.1029/2010JB007503, 2011a.

De Martino, S., Palo, M., and Cimini, G. B.: A statistical study of the Stromboli volcano explosion-quakes before and during 2002-2003 eruptive crisis, J. Geophys. Res., 116, B04303(15), doi:10.1029/2010JB008047, 2011b.

Dibble, R. R., Kyle, P. R., and Rowe, C. A.: Video and seismic observations of Strombolian eruptions at Erebus volcano, Antarctica, J. Volcanol. Geotherm. Res., 177, 619-634, 2008.

Domínguez, T., Zobin, V. M., and Reyes-Davila, G. A.: The fracturing in volcanic edifice before an eruption: The June-July 1998 high frequency earthquake swarm at Volcán de Colima, México, J. Volc. Geotherm. Res., 105, 65-75, 2001.

Elsner, J. B., and Tsonis, A. A.: Singular Spectral Analysis, A New Tool in Time Series Analysis, Plenum Press, 1996.

Fiori, S.: Overview of independent component analysis technique with an application to synthetic aperture radar (SAR) imagery processing, Neural Networks, 16, 453-467, 2003.

Fujita, E., Ukawa, M., and Yamamoto, E.: Subsurface cyclic magma sill expansions in the 2000 Miyakejima volcano eruption: Possibility of two-phase flow oscillation, J. Geophys. Res., 109, B04205, doi:10.1029/2003JB002556, 2004.

Godano, C. and Capuano, P.: Source characterisation of low frequency events at Stromboli and Vulcano Islands (isole Eolie Italy), J. Seism., 3, 393-408, 1999.

Garduño-Monroy, A., Saucedo-Giròn, R., Jiménez, Z., GavilanezRuiz, J. C., Cortes-Cortes, A., and Uribe-Cifuentes, R. M.: La falla Tamazula, limite suroriental del bloque de Jalisco y sus relaciones con el complejo volcanico de Colima. Revista Mexicana de Cien. Geol., 15, 132-144, 1998.

Iwamura, K. and Kaneshima, S.: Numerical simulation of the steamwater flow instability as a mechanism of long-period ground vibrations at geothermal areas, Geophys. J. Int., 163, 833-851, 2005.

Hérault, J. and Ans, B.: Réseaux de neurons á synapses modifiables: Décodage de messages sensoriels composites par une apprentisage non supervise et permanent, C.R. Acad. Sci. Paris III, 525-528, 1984.

Hyvärinen, A., Karhunen, J., and Oja, E.: Independent Component Analysis, John Wiley \& Sons, New York, 2001.

Johnson, J., Aster, R., Jones, K. R., Kyle, P., and McIntosha, B.: Acoustic source characterization of impulsive Strombolian eruptions from the Mount Erebus lava lake, J. Volcanol. Geoth. Res., 177, 673-686, 2008.

Julian, B. R.: Volcanic Tremor: Nonlinear Excitation by Fluid Flow, J. Geophys. Res., 99, 11, 859-877, 1994.

Konstantinou, K. I.: Deterministic non-linear source processes of volcanic tremor signals accompanying the 1996 Vatnajökull eruption, central Iceland, Geophys. J. Int., 148, 663-675, 2002.

Kawanabe, M., Sugiyama, M., Blanchard, G., and Müller, K. R.: A new algorithm of non-Gaussian component analysis with radial kernel functions, Ann. Inst. Stat. Math., 59, 57-75, 2007.

Lin, C. T., Cheng, W. C., and Liang, S. F.: A 3-D surface reconstruction approach based on postnonlinear ICA model, IEEE Trans. 
Neural Netw., 16, 1638-1650, 2005.

Lin, S. and Tung, P.: Application of Modified ICA to Secure Communications in Chaotic Systems - Lecture notes in Computer Science, Springer, 2007.

Luhr, J. F.: Petrology and geochemistry of the 1991 and 1998 1999 lava flows from Volcaán Colima, Mexico, Journ. Volcanol. Geother. Res., 117, 169-194, 2002.

Maurel, A., Ern, P., Zielinska, B. J. A., and Wesfreid, J. E.: Experimental study of selfoscillations in a confined jet, Phys. Rev. E, 54, 3643-3651, 1996.

McNutt, S. R.: Volcanic Seismology, Annu. Rev. Earth. Pl. Sc., 32, 461-491, 2005.

Orihara, Y., Kamogawa, M., Nagao, T., and Uyeda, S.: Independent component analysis of geoelectric field data in the northern Nagano, Japan, P. Jpn. Acad., Series B, 85, 435-442, 2009.

Patanè, D., Di Grazia, G., Cannata, A., Montalto, P., and Boschi E.: Shallow magma pathway geometry at Mt. Etna volcano, Geochem. Geophys. Geosyst., 9, Q12021, doi:10.1029/2008GC002131, 2008.

Palo, M., Ibañez, J. M., Cisneros, M., Bretón, M., Del Pezzo E., Ocaña, E., Orozco, J., and Posadas, A. M.: Analysis of the wavefield properties of the volcanic explosions at Volcán de Colima, Mexico: insight of the source mechanism, Geophys. J. Int., 177, 1383-1398, 2009.

Petrosino, S., Cusano, P., La Rocca, M., Galluzzo, D., OrozcoRojas, J., Bretòn, M., Ibañez J., and Del Pezzo, E.: Source location of long period seismicity at Volcàn de Colima, México, Bull. Volcanol., 73, 887-898, 2011.

Rowe, C., Aster, R., Kyle, P., Schlue, J., and Dibble, R.: Broadband recording of Strombolian explosions and associated very-longperiod seismic signals on Mount Erebus Volcano, Ross Island, Antarctica, Geophys. Res. Lett., 25, 2297-2300, 1998.

Rowe, C. A., Aster, R. C., Kyle, P. R., Dibble, R. R., and Schulue, J. W.: Seismic and acoustic observations at Mount Erebus Volcano, Ross Island, Antarctica, J. Volcanol. Geotherm. Res., 101, 105128, 2000.

Ruiz, M.: Analysis of tremor activity at Mt. Erebus Volcano, Antarctica, M. S. thesis, N. M. Inst. of Min. and Technol., Socorro, 2003.
Stögbauer, H., Kraskov, A., Astakhov, S. A., and Grassberger, P.: Least Dependent Component Analysis Based on Mutual Information, Phys. Rev. E, 70, 066123, doi:10.1103/PhysRevE.70.066123, 2004.

Uyeda, S., Kamogawa, M. and Tanaka, H.: Analysis of electrical activity and seismicity in the natural time domain for the volcanic-seismic swarm activity in 2000 in the Izu Island region, Japan, J. Geophys. Res., 114, B02310, doi:10.1029/2007JB005332, 2009.

Varotsos, P. and Alexopoulos, K.: Physical properties of the variations of the electric field of the earth preceding earthquakes, I. Tectonophysics, 110, 73-98, 1984a.

Varotsos, P. and Alexopoulos, K.: Physical properties of the variations of the electric field of the earth preceding earthquakes, II, Determination of epicenter and magnitude, Tectonophysics, 110 , 99-125, 1984b.

Varotsos, P., Sarlis, N., and Skordas, E.: Long range correlations in the electric signals that precede rupture, Phys. Rev. E, 66, 011902, doi:10.1103/PhysRevE.66.011902, 2002.

Varotsos, P., Sarlis, N., Skordas, E., Tanaka, H., and Lazaridou, M.: Entropy of seismic electric signals: Analysis in natural time under time reversal, Phys. Rev. E, 73, 031114 doi:10.1103/PhysRevE.73.031114, 2006.

Villermaux, E. and Hopfinger, E. J.: Self-sustained oscillations of a confined jet: a case study for non-linear delayed saturation model, Physica D, 72, 230-243, 1994.

Wall, M. E., Rechtsteiner, A., and Rocha, L. M.: Singular value decomposition and principal component analysis, in: A Practical Approach to Microarray Data Analysis, edited by: Berrar, D. P., Dubitzky, W., Granzow, M., Norwell, MA: Kluwer, 91-109, http://public.lanl.gov/mewall/kluwer2002.html, 2003.

Woodhouse, J.: Self-sustained musical oscillators, in: Mechanics of Musical Instruments, Springer, New York, 1996.

Zobin, V. M., Navarro, C., Reyes-Dávil, G., Orozco, J., Bretón, M. Tellez, A., Reyes-Alfaro, G., and Vazquez, H.: The methodology of quantification of volcanic explosions from broad-band seismic signals and its application to the 2004-2005 explosions at Volcán de Colima, Mexico, Geophys. J. Int., 167, 467-478, 2006. 